\title{
Founder effect in the Horn of Africa for an insulin receptor mutation that may impair receptor recycling
}

\author{
E. Raffan • M. A. Soos • N. Rocha • A. Tuthill • A. R. Thomsen • C. S. Hyden • \\ J. W. Gregory • P. Hindmarsh • M. Dattani • E. Cochran • J. Al Kaabi • P. Gorden • \\ I. Barroso • N. Morling $\cdot$ S. O'Rahilly $\cdot$ R. K. Semple
}

Received: 20 September 2010 / Accepted: 7 January 2011 /Published online: 12 February 2011

(C) The Author(s) 2011. This article is published with open access at Springerlink.com

\begin{abstract}
Aims/hypothesis Genetic insulin receptoropathies are a rare cause of severe insulin resistance. We identified the Ile119Met missense mutation in the insulin receptor INSR gene, previously reported in a Yemeni kindred, in four unrelated patients with Somali ancestry. We aimed to investigate a possible genetic founder effect, and to study the mechanism of loss of function of the mutant receptor. Methods Biochemical profiling and DNA haplotype analysis of affected patients were performed. Insulin receptor expression in lymphoblastoid cells from a homozygous p.Ile119Met INSR patient, and in cells heterologously expressing the mutant receptor, was examined. Insulin binding, insulinstimulated receptor autophosphorylation, and cooperativity
\end{abstract}

E. Raffan and M.A. Soos contributed equally to this study.

Electronic supplementary material The online version of this article (doi:10.1007/s00125-011-2066-z) contains supplementary material, which is available to authorised users.

E. Raffan · M. A. Soos · N. Rocha · A. Tuthill · C. S. Hyden ·

I. Barroso $\cdot$ S. O'Rahilly $\cdot$ R. K. Semple $(\bowtie)$

University of Cambridge Metabolic Research Laboratories,

Institute of Metabolic Science, University of Cambridge,

Addenbrooke's Hospital B289,

Cambridge CB2 0QR, UK

e-mail: rks16@cam.ac.uk

\section{A. R. Thomsen $\cdot$ N. Morling}

Section of Forensic Genetics, Department of Forensic Medicine,

Faculty of Health Sciences, University of Copenhagen,

Copenhagen, Denmark

\section{J. W. Gregory}

Department of Child Health,

Wales School of Medicine,

Cardiff University,

Cardiff, UK and $\mathrm{pH}$ dependency of insulin dissociation were also assessed. Results All patients had biochemical profiles pathognomonic of insulin receptoropathy, while haplotype analysis revealed the putative shared region around the INSR mutant to be no larger than $28 \mathrm{~kb}$. An increased insulin proreceptor to $\beta$ subunit ratio was seen in patient-derived cells. Steady state insulin binding and insulin-stimulated autophosphorylation of the mutant receptor was normal; however it exhibited decreased insulin dissociation rates with preserved cooperativity, a difference accentuated at low $\mathrm{pH}$. Conclusions/interpretation The p.Ile119Met INSR appears to have arisen around the Horn of Africa, and should be sought first in severely insulin resistant patients with ancestry from this region. Despite collectively compelling
P. Hindmarsh $\cdot$ M. Dattani

Institute of Child Health, University College London,

London, UK

E. Cochran · P. Gorden

Clinical Endocrinology Branch, National Institute of Diabetes,

Digestive and Kidney Diseases,

Bethesda, MD, USA

J. Al Kaabi

Faculty of Medicine and Health Sciences,

United Arab Emirates University,

Al-Ain, United Arab Emirates

I. Barroso

The Wellcome Trust Sanger Institute,

Wellcome Trust Genome Campus,

Cambridge, UK 
genetic, clinical and biochemical evidence for its pathogenicity, loss of function in conventional in vitro assays is subtle, suggesting mildly impaired receptor recycling only.

Keywords Africa - Diabetes - Genetics - Insulin receptor . Insulin resistance $\cdot$ Receptor recycling $\cdot$ Type A insulin resistance

$\begin{array}{ll}\text { Abbreviations } \\ \text { CHO } & \begin{array}{l}\text { Chinese hamster ovary } \\ \text { EBVL }\end{array} \\ & \begin{array}{l}\text { Epstein-Barr virus transformed lymphoblastoid } \\ \text { cells }\end{array} \\ \text { LOD } & \begin{array}{l}\text { Logarithm (base 10) of the odds } \\ \text { SBE }\end{array} \\ \text { SNingle base extension } \\ \text { SNP } & \text { Single nucleotide polymorphism }\end{array}$

\section{Introduction}

Insulin resistance is a common consequence of obesity, and is frequently a prelude to frank type 2 diabetes [1]. Uncommonly, severe insulin resistance is seen in lean people, often presenting with features of ovarian hyperandrogenism and ovulatory dysfunction in women before hyperglycaemia ensues $[2,3]$. In most cases, such severe insulin resistance is believed to have a genetic basis, and around $10-20 \%$ of such patients have loss-of-function mutations in the insulin receptor INSR gene [4].

Since the first description of INSR mutations in patients with severe insulin resistance in $1988[5,6]$, nearly 100 allelic variants have been described [4], and many of these have been characterised in vitro. Such studies were the basis of the classification by Taylor and colleagues in 1992 of pathogenic INSR mutations into five classes, defined by defects in receptor expression, trafficking to the cell surface, insulin binding, signal transduction or receptor recycling, respectively [7]. Although many mutant receptors with defective trafficking and/or insulin binding and/or signal transduction have been described, mutations predominantly affecting receptor endocytosis or recycling are rare. The best studied examples are the Lys460Glu [8] and Ser462Asn [9] mutations, which perturb a critical hinge region of the insulin binding domain of the receptor [10], leading to impaired dissociation of bound insulin in acidic conditions [8,9], and the Arg252Cys mutation, which impairs receptor endocytosis [11].

Genetic defects in the insulin receptor produce a clinical spectrum of abnormality. Biallelic mutations most commonly produce Donohue or Rabson-Mendenhall syndromes, disorders with marked impairment of linear growth, soft tissue overgrowth and extreme metabolic derangements that lead to mortality between infancy and early adulthood $[2,3]$. The less severe end of the spectrum comprises severe insulin resistance usually presenting peripubertally in females with hyperandrogenism, oligomenorrhoea and acanthosis nigricans [2, 3]. Heterozygous mutations in the intracellular domain of the insulin receptor are most commonly found in this setting, transmitting disease with autosomal dominant inheritance, but a minority of such patients have milder, biallelic mutations in the extracellular domain with autosomal recessive inheritance [4].

One reported cause of such milder, autosomal recessive disease is the p.Ile119Met mutation in the alpha subunit, reported in a single Yemeni kindred $[12,13]$. Although a case was made for the pathogenicity of the mutant based on a two point logarithm (base 10) of the odds (LOD) score derived from this single family [12], no functional studies of the mutant in vitro or ex vivo have been reported. Since the index report we have identified four unrelated patients of Somali ancestry with the same INSR mutation, which did not occur in any other patients with severe insulin resistance. We thus set out to assess the mechanism of loss of function of the Ile119Met mutant insulin receptor, and, given the close geographical proximity of Somalia and the Yemen in the region of the Horn of Africa, to investigate a likely geographic founder effect for this mutation.

\section{Methods}

Patients All patients were studied with informed consent in line with procedures approved either by the local research ethics committee in Cambridge, UK, or the institutional review board of the National Institute of Diabetic and Digestive and Kidney Diseases. Rabson-Mendenhall syndrome was defined by prepubertal presentation with classical syndromic features and survival beyond 3 years old. Type A insulin resistance denotes severe hyperinsulinaemia, acanthosis nigricans and hyperandrogenism, presenting post- or peri-pubertally in girls.

Biochemical assays Blood was drawn after a $12 \mathrm{~h}$ fast, and plasma stored at $-20^{\circ} \mathrm{C}$. Insulin, leptin and adiponectin were assayed using previously described dissociationenhanced lanthanide fluorescence immunoassays [14]. All other assays were undertaken in accredited diagnostic laboratories of referring hospitals.

Molecular genetic studies Genomic DNA was extracted from peripheral blood leucocytes before PCR amplification of all exons of the INSR and $50 \mathrm{bp}$ of their flanking sequences. Primer sequences are available on request. PCR products were purified using Agencourt CleanSEQ reagents (Agencourt Bioscience Corporation, Beverly, MA, USA) 
and sequenced bidirectionally on an ABI 3730 DNA sequencer (Applied Biosystems, Warrington, UK). Sequence analysis was performed using Softgenetics Mutation Surveyor (State College, PA, USA).

DNA from 100 unrelated, healthy Somalian immigrants to Denmark was typed for the INSR Ile119Met variant using PCR and single base extension (SBE) [15]. Exon 2 of INSR was amplified by PCR as described above and treated with ExoSAP-IT (USB, Cleveland, OH, USA) to remove single stranded nucleotides and excess dNTPs. The Ile119Met mutation was typed using SBE with the SNapShot kit (Applied Biosystems). The following primer was used for the SBE (the single nucleotide polymorphisms [SNPs] are underlined): Ile119Met (reverse): GAGCTCATTGTTCTTCTC-G/C. The SBE reaction was performed in triplex. Excess ddNTPS were removed with shrimp alkaline phosphatase before samples were run on an ABI Prism ABI3130 genetic analyser (Applied Biosystems). Allele determination was undertaken using Genescan 3.7 and Genotyper 3.7 software (Applied Biosystems) [15]. DNA from two patients was applied as positive control and both were homozygous for the Ile119Met mutation. INSR sequence data from 179 individuals of different ethnic origins in the 1000 Genomes Project pilot 1 data release (April 2009, 100328; $\mathrm{ftp} / / / \mathrm{ftp} .1000$ genomes.ebi.ac.uk/vol1/ftp/pilot_data/release/ 2010_03/pilot1/README_SRP000031.2010_03_snps) and exome-wide sequencing data from 354 Europid individuals (I. Barroso, unpublished data) were additionally interrogated for the presence of the p.Ile119Met and p.Arg1039X mutations.

Patients were genotyped for three microsatellite markers flanking INSR (D19S916, D19S873, D19S216); an unannotated microsatellite consisting of a tandem AC repeat within intron 1 of the insulin receptor gene (position 19:7269388-7269437, bounded by rs67146219 and rs711177190, Ensembl assembly GRCh37, named 25AC in Table 2); and SNPs in introns 1 and 2 chosen for having a minor allele frequency $\geq 40 \%$ in the Yoruba population in Ibadan, Nigeria (YRI) (the International HapMap Project [16] accessed 17 May 2010) (rs7254487, rs6210958, rs7248939, rs11671297, rs4804433, rs3852876, rs57930737, and rs4499341). Microsatellites were amplified using GoTaq Green chemistry (Promega, Madison, WI, USA) according to the manufacturer's instructions using a FAM fluorescent tag on the reverse primer. Products were diluted and mixed with GeneScan 500LIZ Size Standard (Applied Biosystems) and run on an ABI 3730 DNA Analyser (Applied Biosystems). Allele determination was undertaken using GeneMapper software (Applied Biosystems). For SNP genotyping, DNA was amplified using GoTaq Green chemistry, sequenced using a BigDye Terminator v3.1 Cycle Sequencing kit (Applied Biosystems), run on the ABI 3730 DNA Analyser, and genotype calls were made using Sequencher software (Gene
Codes Corporation, Ann Arbor, MI, USA). Primer sequences are available upon request.

Structural modelling The effect of the Ile119Met mutation was assessed structurally using SWISS-MODEL and the Swiss-PdbViewer [17] (www.expasy.org/spdbv/). The pdb file used for modelling was $2 \mathrm{hr} 7$ [18].

Lymphoblastoid cell culture Epstein-Barr virus transformed lymphoblastoid (EBVL) cell lines were generated from patient and control whole blood by the European Collection of Cell Cultures (Porton Down, UK) and maintained in RPMI-1640 medium (Sigma-Aldrich, St Louis, MO, USA) supplemented with $10 \%$ (wt/vol.) fetal bovine serum (FBS), $2 \mathrm{mmol} / \mathrm{l} \mathrm{L}$-glutamine and $100 \mathrm{U} / \mathrm{l}$ penicillin and $100 \mu \mathrm{g} / \mathrm{ml}$ streptomycin (all from Sigma-Aldrich).

Site-directed mutagenesis and expression of mutant receptor in vitro Point mutations were introduced using the QuikChangeXL Site-Directed Mutagenesis Kit (Stratagene, La Jolla, CA, USA) according to the manufacturer's instructions. All constructs were in the pRc.CMV expression vector (Invitrogen, Leek, the Netherlands), and the resulting mutations were verified by sequencing. For functional studies, Chinese hamster ovary $(\mathrm{CHO})$ cells maintained at $37^{\circ} \mathrm{C}$ in Nutrient F-12 Ham's medium (Sigma-Aldrich, Irvine, UK) supplemented with $10 \%$ (wt/vol.) fetal calf serum, 1,000 U/1 penicillin, $0.1 \mathrm{~g} / 1$ streptomycin, and $2 \mathrm{mmol} / \mathrm{l}$ L-glutamine were transfected using FuGENE (Roche) as transfection reagent. All experiments were performed between 36 and $48 \mathrm{~h}$ after transfection.

Insulin-induced receptor autophosphorylation Transfected cells were serum-starved for $6 \mathrm{~h}$, and then stimulated with $100 \mathrm{nmol} / 1$ insulin for $5 \mathrm{~min}$ at $37^{\circ} \mathrm{C}$. Following stimulation, cells were washed with ice cold PBS and solubilised in $5 \mu \mathrm{l}$ lysis buffer $/ 1 \mathrm{~cm}^{2}$ confluent cells. Lysis buffer contained $50 \mathrm{mmol} / 1$ Hepes, $150 \mathrm{mmol} / \mathrm{l} \mathrm{NaCl}$, $30 \mathrm{mmol} / 1 \mathrm{NaF}, 10 \mathrm{mmol} / 1 \mathrm{Na}_{4} \mathrm{P}_{2} \mathrm{O}_{7}, 1 \mathrm{mmol} / 1 \mathrm{Na}_{2} \mathrm{VO}_{4}$, 1\% (vol./vol.) Triton X100, $10 \mathrm{mmol} / \mathrm{l}$ EDTA and 1 tablet of protease inhibitor mini complete cocktail (Roche, Mannheim, Germany) per $7 \mathrm{ml}$ buffer. Protein concentration was quantified using a Bio-Rad $\mathrm{D}_{\mathrm{C}}$ protein assay (Bio-Rad Laboratories, Hercules, CA, USA). Cell lysates were electrophoresed under reducing, denaturing conditions in $8 \%(\mathrm{wt} / \mathrm{vol}$.) polyacrylamide gels (SDS-PAGE). Proteins were transferred to Immobilon-P polyvinylidene fluoride membranes (Millipore, Bedford, MA, USA), and membranes were probed with the rabbit anti-insulin receptor polyclonal antibody followed by horseradish peroxidase-conjugated secondary antibody. Antibody binding was assessed using enhanced chemiluminescence (Amersham Pharmacia Biotech, Little Chalfont, UK) and 
Alpha-Ease densitometry was performed to quantify band intensity.

Insulin binding assays Insulin binding was determined by washing transiently-transfected $\mathrm{CHO}$ cells in 24 -well plates twice with PBS prior to incubation with $\left[{ }^{125} \mathrm{I}\right]$ insulin $(3 \times$ $\left.10^{-11}-4 \times 10^{-11} \mathrm{~mol} / \mathrm{l}\right)$ together with unlabelled insulin for $6 \mathrm{~h}$ at $4^{\circ} \mathrm{C}$ in binding buffer $(100 \mathrm{mmol} / 1$ HEPES $(\mathrm{pH} 7.8)$, $120 \mathrm{mmol} / \mathrm{l} \mathrm{NaCl}, 1 \mathrm{mmol} / \mathrm{l}$ EDTA, $15 \mathrm{mmol} / \mathrm{l}$ sodium acetate, $1.2 \mathrm{mmol} / 1 \mathrm{MgSO}_{4}, 10 \mathrm{mmol} / \mathrm{l}$ glucose, and $1 \%$ [wt/vol.] BSA). Cells were then washed twice with ice cold PBS and solubilised in $0.03 \%$ (wt/vol.) sodium dodecyl sulfate for determination of cell-bound radioactivity in a $\gamma$ counter (1282 Compugamma CS Universal $\gamma$-Counter, LKB Wallac, Turku, Finland). Nonspecific binding determined in the presence of $1 \mu \mathrm{mol} / 1$ unlabelled insulin was subtracted and results were standardised to that bound by the wild-type receptor.

Insulin dissociation assays For insulin dissociation studies, $60,000 \mathrm{CHO}$ cells were seeded per well of five 24 well plates and transfected with $400 \mathrm{ng}$ of the appropriate plasmid using polyethylimine, $12 \mathrm{~h}$ after seeding, before dissociation studies, when cells were at $70-90 \%$ confluence.

To assess the insulin dissociation rate from heterologously expressed receptors, plates were placed on ice, before aspiration of medium and washing twice with PBS. $150 \mu \mathrm{l}$ of binding buffer $(120 \mathrm{mmol} / 1 \mathrm{NaCl}, 2.5 \mathrm{mmol} / \mathrm{K} \mathrm{KCl}$, $15 \mathrm{mmol} / \mathrm{l} \mathrm{Na}$ acetate, $1 \mathrm{mmol} / \mathrm{l} \mathrm{EDTA}, 1.2 \mathrm{mmol} / 1 \mathrm{MgSO}_{4}$, $10 \mathrm{mmol} / 1$ glucose, $1 \%$ (wt/vol). BSA, $50 \mathrm{mmol} / 1 \mathrm{HEPES}$, $\mathrm{pH}$ 7.8) was added to all wells, followed by $100 \mu$ l binding buffer with or without cold insulin as appropriate. To the relevant wells $50 \mu$ l of ${ }^{125}$ I-labelled insulin $(10-15,000 \mathrm{cpm})$ was then added before incubation at $4^{\circ} \mathrm{C}$ with shaking for 4 $6 \mathrm{~h}$. Plates were then put on ice, buffer was aspirated and cells were washed twice with ice cold PBS. Cells in one plate were then solubilised in $200 \mu 10.03 \%$ (wt/vol.) SDS for $30 \mathrm{~min}$ at room temperature before counting in a $\gamma$ counter to determine insulin binding prior to dissociation.

For cooperativity studies, $250 \mu \mathrm{l}$ of dissociation buffer $(120 \mathrm{mmol} / \mathrm{l} \mathrm{NaCl}, 4.5 \mathrm{mmol} / \mathrm{l} \mathrm{KCl}, 1 \mathrm{mmol} / \mathrm{l} \mathrm{EDTA}$, $1.2 \mathrm{mmol} / 1 \mathrm{MgSO}_{4}, 10 \mathrm{mmol} / 1$ glucose, $1 \%$ [wt/vol.] BSA, and $50 \mathrm{mmol} / \mathrm{l}$ HEPES, $\mathrm{pH}$ 7.8) was added to each well with additional cold insulin to final concentrations of $0,0.1$ and $10 \mu \mathrm{mol} / 1$ as appropriate, prior to incubation for $5 \mathrm{~min}$ at $4^{\circ} \mathrm{C}$. Medium was then removed for counting before washing of cells with ice cold PBS and solubilisation and counting as before. For studies of the $\mathrm{pH}$ dependency of insulin dissociation buffers containing $120 \mathrm{mmol} / \mathrm{l} \mathrm{NaCl}$, $4.5 \mathrm{mmol} / 1 \mathrm{KCl}, 1 \mathrm{mmol} / 1 \mathrm{EDTA}, 1.2 \mathrm{mmol} / 1 \mathrm{MgSO}_{4}$, $10 \mathrm{mmol} / 1$ glucose, $1 \%$ (wt/vol.) BSA, and either $100 \mathrm{mmol} / \mathrm{l} \mathrm{MES}$ (for $\mathrm{pH}$ 5.5), ACES (for $\mathrm{pH}$ 6.2), HEPES (for $\mathrm{pH}$ 7.0) or TAPS (for $\mathrm{pH} 7.8$ ) were used, and no additional cold insulin was added during dissociation. All chemical reagents were purchased from Sigma unless otherwise indicated.

Statistics Paired $t$ tests were used to compare insulin dissociation at each $\mathrm{pH}$ tested. In cooperativity studies, two way ANOVA was used to compare insulin binding over time in the differently transfected cells and at different insulin concentrations.

\section{Results}

Case histories Clinical and biochemical features of all patients studied are summarised in Table 1, and more detailed clinical summaries are provided as Electronic Supplementary Material (ESM). Although only 10-20\% of postpubertal patients with severe insulin resistance harbour insulin receptor mutations [4], all patients we describe had strikingly elevated levels of serum adiponectin, SHBG and/or IGFBP1, where measured, as well as a normal lipid profile, a pattern which we have found to be pathognomonic of insulin receptoropathy $[19,20]$. Indeed, the adiponectin level in patient 4 , at $98 \mathrm{mg} / \mathrm{l}$, is the highest level our laboratory has recorded, and is nearly three times higher than the highest value recorded in 900 healthy Europid controls. Thus, on biochemical grounds alone, there is compelling evidence that all five patients have insulin receptoropathy [7].

Genetic studies Patients 1, 2, 3 and 4 were all homozygotes for the INSR p.Ile119Met (c.576C $>$ G) mutation (numbered according to the sequence of the mature receptor; Fig. 1a). Patient 5 was a compound heterozygote for the p.Ile119Met and p.Arg1039X (c.33342C > T) mutations, the p.Ile119Met variant having been inherited from his Somali father, and the p.Arg1039X from his French mother. p.Arg1039X, although not previously described, was not detected in more than 400 Europid control genomes and exomes. Cosegregation between homozygosity for INSR Ile119Met and severe insulin resistance has previously been reported in the family of Patient 1 . No family members were available for study for patients 2,3 , and 4 , while patient 5 had no siblings. Ile119 is a strongly conserved residue in the L1 domain of the alpha subunit of the insulin receptor, where it lies in the central beta sheet of the fifth strand, its side chain directed inwards towards the core of the L1 domain, and substitution for methionine is predicted to alter packing within the barrel (Fig. 1b, c).

To determine whether INSR Ile119Met is a common variant in the Somali population we screened 100 unrelated Somali controls, but failed to identify any mutant alleles, giving $95 \%$ confidence that the mean allele frequency in the 


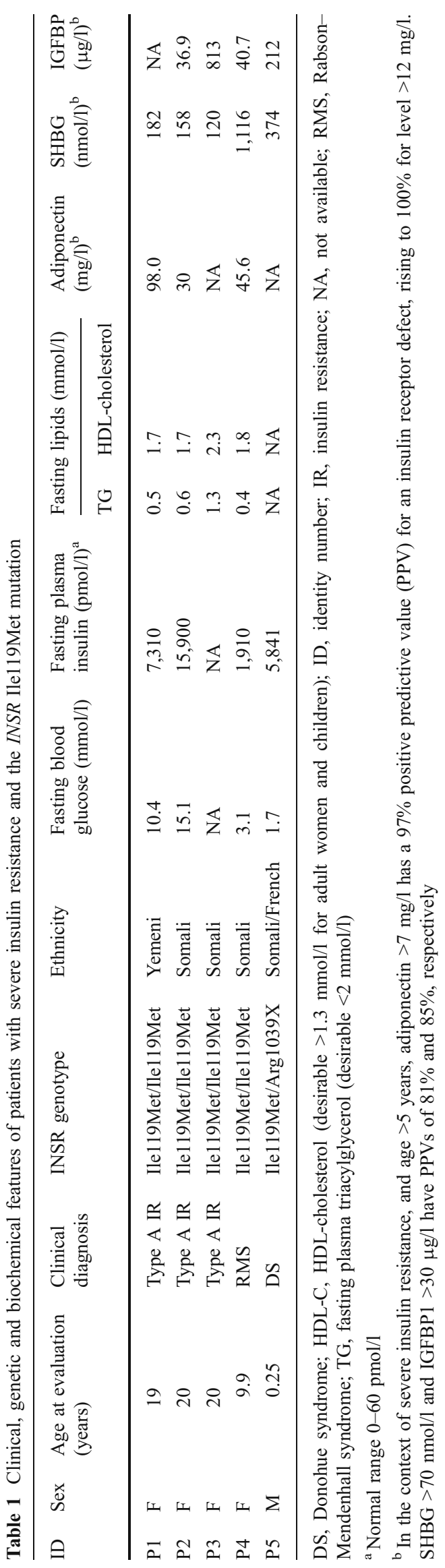

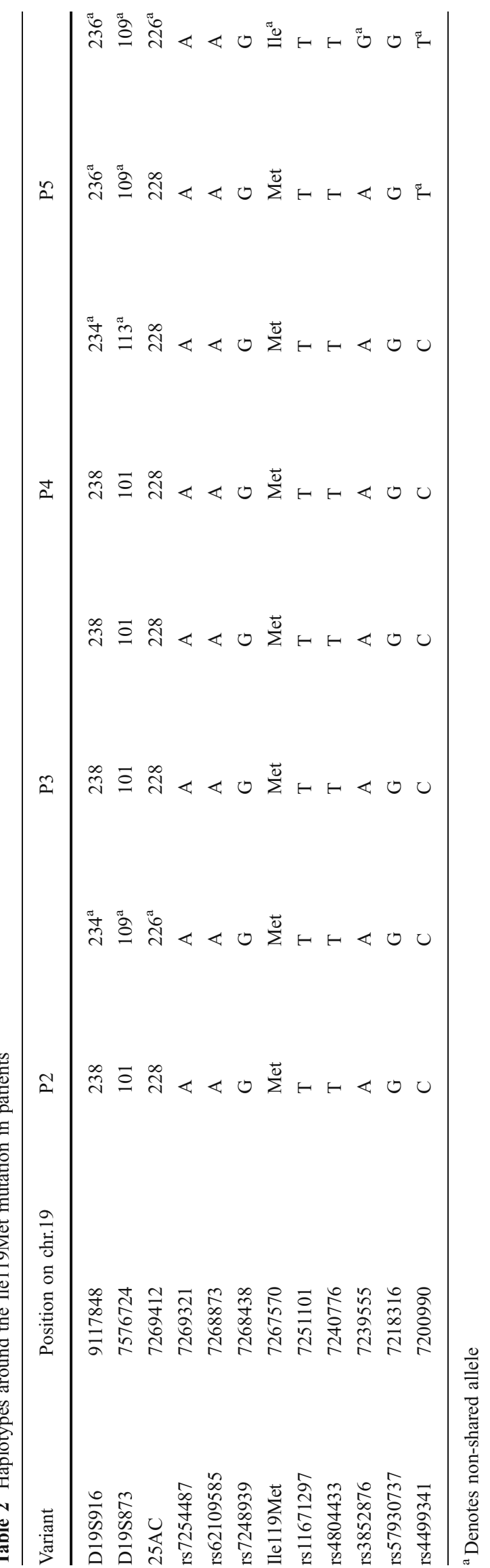




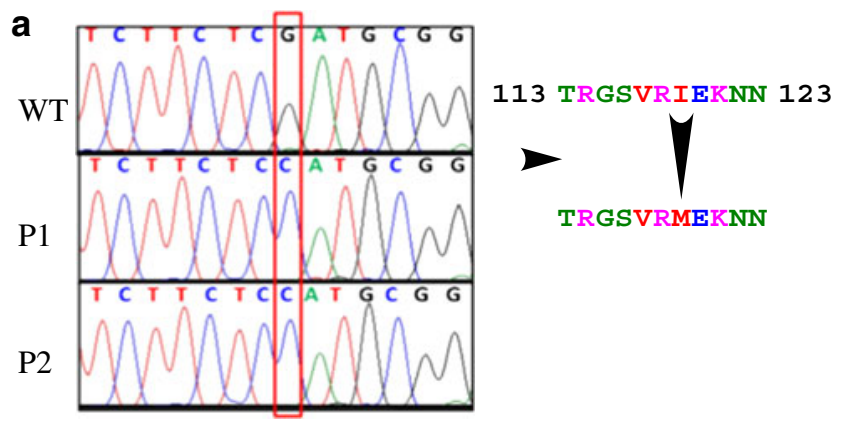

b

Human 103 ELGLYNLMNITRGSVRTEKNNELCYLATIDW 134 Mouse ELGLYNLMNITRGSVR IEKNNELCYLATIDW Danio rerio EIGLHSLMNITRGAVRVEKNPDLCYLSTLDW Xenopus DIGLYSLTNILNGAVR IERNQELCHISTIDW Aedes aegypti EIGLISLMDITRGGVRIEKNPKLCFANTIDW Drosophila DLGLHKLRSITRGGVR IEKNHKLCYDRTIDW C. elegans EIGLDKLSVIRNGGVRIIDNRKLCYTKTIDW $:: * *$ * * .***: * .**. * : **

C

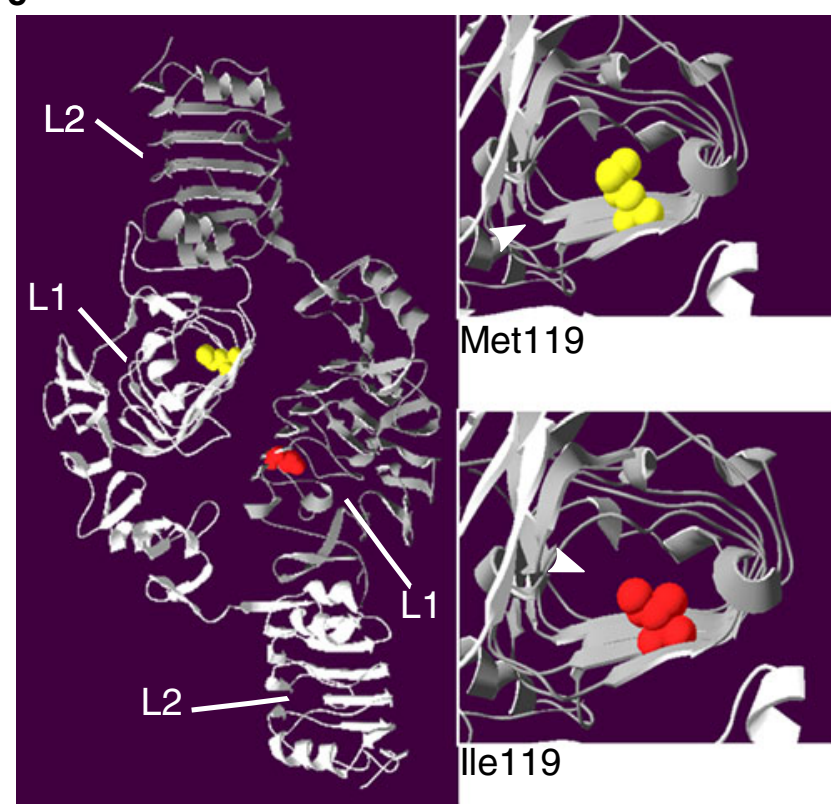

Fig. 1 Identification and location of the Ile119Met INSR mutation. a Genomic DNA sequence of Patient 2, showing homozygous INSR c.576C $>\mathrm{G}$ mutation with resulting p.Ile119Met substitution. b Phylogenetic conservation of Ile119. c Ile119 (red) and Met119 (yellow) represented on different alpha subunits in a detail of the crystal structure of the insulin receptor alpha subunit dimer (L1 and L2 are EGF-like domains), with close-up views down the barrel of the L1 domain showing the modest change caused by substitution of Ile119 by methionine. WT, wild type

Somali population is $\leq 1.5 \%$ [21]. We then undertook further studies in affected patients to seek an informative haplotype including microsatellites and SNPs (Table 2). Despite screening a wide range of microsatellites and SNPs with mean allele frequencies reported to be $\geq 40 \%$ in the Yoruba population, it was not possible definitively to identify a shared haplotype. However, it was possible to establish an upper size limit of $28 \mathrm{~kb}$ for the putative shared haplotype, suggesting that the common ancestry of our patients is ancient.

Expression and function of the Ile119Met INSR Expression of the Ile119Met INSR was first determined in EBVL cells from Patient 1. Compared with controls, expression of the mature $\beta$ subunit of the receptor was normal; however there was a consistent slight increase in the proreceptor to mature $\beta$ subunit ratio (Fig. 2a). On heterologous expression of the mutant receptor in $\mathrm{CHO}$ cells, a similar pattern was often, though not invariably, seen, suggesting mildly impaired proreceptor processing (Fig. 2b). Despite this, insulininduced receptor autophosphorylation was grossly normal (Fig. 2b).

Insulin binding by the Ile119Met INSR Steady state insulin binding by both EBVLs from one patient with homozygous p.Ile119Met INSR mutations (Fig. 3a), and by CHO cells heterologously expressing the mutant receptor (Fig. 3b-d), was normal, in keeping with the normal receptor autophosphorylation. However, in view of the convincing receptoropathy phenotype of all patients, we elected to investigate insulin binding by the mutant receptor in more detail. It is well established that increasing the level of receptor occupancy by addition of unlabelled insulin alters the insulin dissociation rate [22-24]. With a wild type receptor, addition of insulin at concentrations up to $5,000 \mathrm{ng} / \mathrm{ml}$ $(861 \mathrm{nmol} / \mathrm{l})$ accelerates the rate at which bound ${ }^{125}$ I-insulin dissociates from the receptor - a phenomenon termed 'negative cooperativity' - while addition of insulin at concentrations up to $50,000 \mathrm{ng} / \mathrm{ml}(8,610 \mathrm{nmol} / \mathrm{l})$ reduces this-termed 'positive cooperativity'. As Ile119 is near the interface between adjacent $\alpha$ subunits, it seemed possible that it might play a role in mediating the cooperative interactions between insulin binding sites. However, although insulin dissociation rates were indeed slower for the mutant receptor than the wild type receptor in all conditions, both types of cooperativity were preserved (Fig. 4).

After insulin binding to its receptor,the ligand-receptor complex is internalised and routed to acidified endosomes, where it may either be degraded or recycled to the plasma membrane after insulin dissociation. Thus, specific impairment of insulin dissociation in acidic conditions would be predicted to impair receptor recycling, potentially significantly reducing cell surface insulin receptor expression in the face of tonic insulin action. Such a phenomenon has been described for the Lys460Glu and Ser462Asn mutant insulin receptors $[8,9]$. In closely similar studies, the mild reduction in dissociation rate of insulin from the Ile119Met mutant receptor was also found to be increased at low $\mathrm{pH}$ (Fig. 5), although the magnitude of this effect was smaller than reported for the Lys460Glu and Ser462Asn mutants. 
a

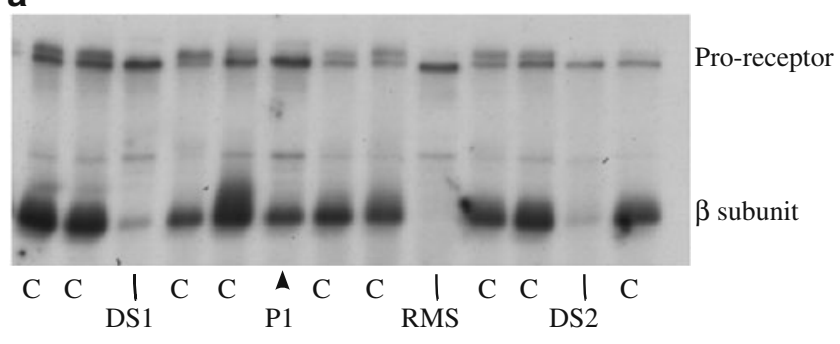

b

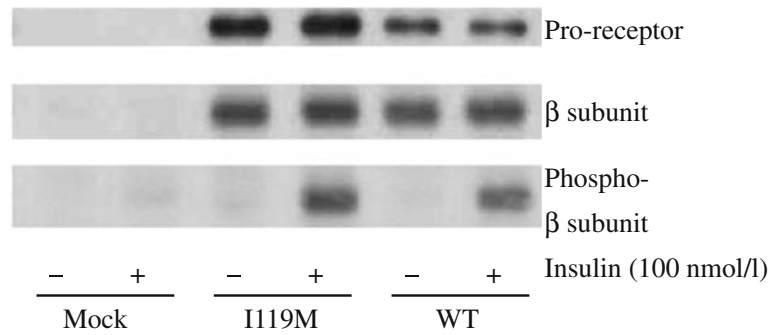

Fig. 2 Expression and insulin-induced autophosphorylation of the Ile119Met insulin receptor. a Expression of the insulin receptor in lymphoblastoid cells from Patient 1 (P1), from healthy controls (C), or from patients with Donohue syndrome (DS): DS1 is a compound heterozygote for p.Cys274Tyr/p.Arg1174Trp INSR mutations; DS2 is a compound heterozygote for fs.108(109X)/p.Gln272X INSR mutations, or Rabson-Mendenhall syndrome (RMS), with compound heterozygous p.His209Arg/p.Gly359Ser INSR mutations. Cell lysates were immunoprecipitated with 83-14 anti $\alpha$ subunit antibody prior to immunoblotting with anti $\beta$ subunit antibody. b Heterologous overexpression of wild-type (WT) or mutant INSR in CHO cells, and receptor autophosphorylation in response to insulin. IP: 83-14 mAb; Blot: anti-InsR b subunit (Santa Cruz)

\section{Discussion}

Over the past 22 years, since the index reports of loss-offunction mutations in the human insulin receptor associated with extreme insulin resistance, more than 100 pathogenic mutations have been described [4]. Relatively few recurring mutations have been reported, although in our own practice we have identified the Pro1178Leu variant in six unrelated Europid patients, adding to the index Japanese report, and the Pro193Leu variant in unrelated Saudi and Afghan families. No geographical founder effects have been demonstrated. Thus our finding of the p.Ile119Met variant in five unrelated patients, all of whom trace ancestry to Somalia or the Yemen, is striking. Indeed, this mutation has been found in all the Somali patients referred to us with extreme insulin resistance, but in no other patient. On these grounds alone, we believe this represents a founder effect in the region of the Horn of Africa. Although we sought to corroborate this by comparing the haplotype around the mutation between patients, lack of variability in markers around the mutation locus meant that we could only establish an upper size limit of $28 \mathrm{~kb}$ for the putative ancestral haplotype, suggesting that any such founder effect must be ancient.
The previous report of the p.Ile119Met mutation associated with extreme insulin resistance included determination of a LOD score of between 3.4 and 4.6, depending on the allele frequency in the population. Our demonstration here, that none of 100 Somali controls carries the mutation, suggests that the higher end of this range is appropriate, providing strong genetic evidence for the pathogenicity of the mutation. We have now determined that patients homozygous for the Ile119Met variant not only have extreme insulin resistance, but also have a biochemical phenotype - extreme hyperinsulinaemia, high adiponectin, SHBG and IGFBP1, and normal lipid profile-which we have found to be pathognomonic for insulin receptor dysfunction $[19,20]$. We thus believe that the collective clinical, genetic and biochemical evidence that the Ile119Met INSR allele severely impairs insulin receptor function in vivo is incontrovertible.

Nevertheless, there have been no reports to date of in vitro characterisation of the Ile119Met mutant receptor. We now report such studies, and surprisingly the in vitro defect is very subtle. Most alpha subunit mutations that have been studied to date either impair proreceptor processing and thus cell surface expression of mature receptors, or severely affect insulin binding to the receptor $[4,7]$. However, insulin binding in both primary cells from an Ile119Met INSR homozygous patient, and in cells heterologously expressing a

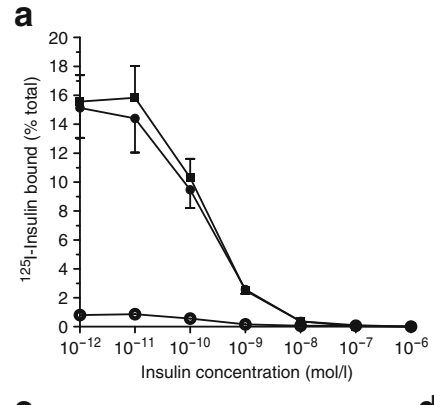

C

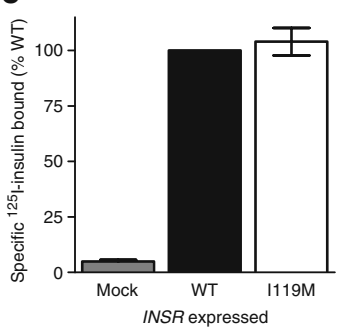

b

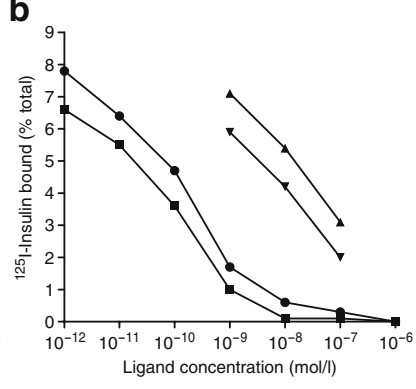

d

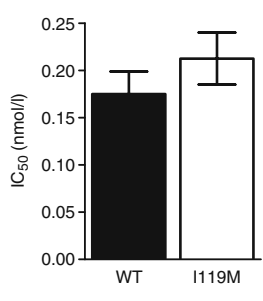

Fig. 3 Insulin binding by the Ile119Met (I119M) insulin receptor. a Insulin and IGF-1 binding by lymphoblastoid cells from Patient 1 and a wild-type (WT) control and (b) Insulin binding by wild-type and Ile119Met mutant insulin receptor after overexpression in CHO cells (insulin: black circles, wild-type; black squares, Ile119Met; white circles, mock. IGF-1: upwards triangles, WT; downwards triangles, Ile119Met.) c Maximum steady state insulin binding by WT and Ile119Met mutant insulin receptors. d IC $_{50}$ for insulin binding for wild-type and Ile119Met mutant insulin receptors 

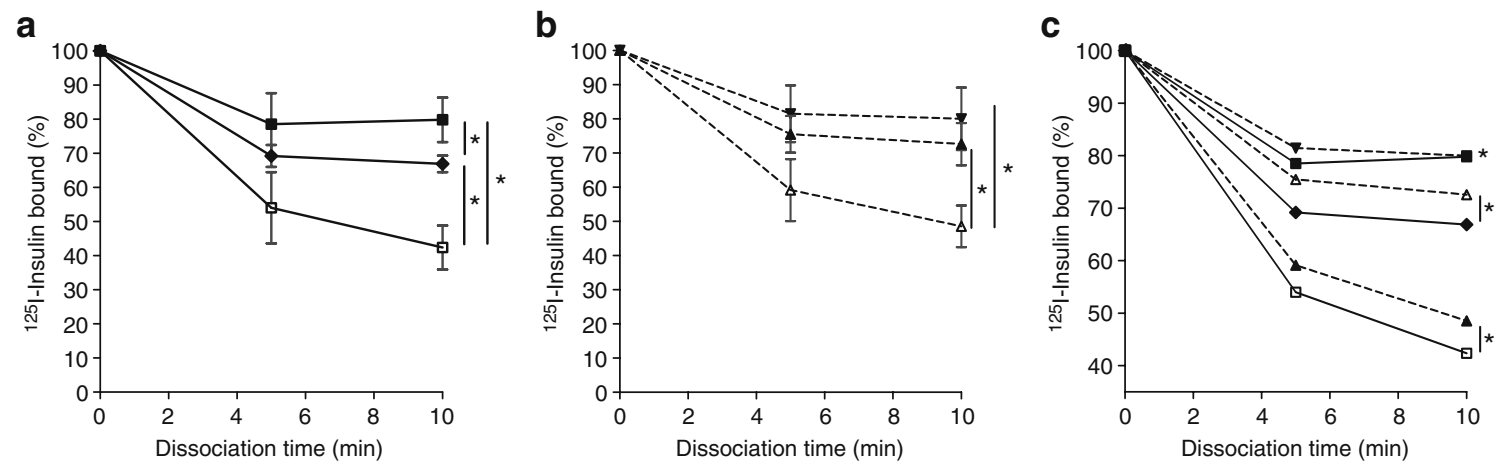

Fig. $4{ }^{125}$ I-insulin dissociation rates and cooperativity of insulin binding for the Ile119Met insulin receptor. Insulin dissociation rate, showing positive and negative cooperativity for (a) wild-type and (b) Ile119Met insulin receptor overexpressed in $\mathrm{CHO}$ cells. c Reduced insulin dissociation from the Ile119Met mutant insulin receptor. $\left({ }^{*} p<\right.$

the mutant receptor, showed normal steady state insulin binding, although there was very subtle evidence of aberrant processing of the proreceptor in both situations, and insulinstimulated receptor autophosphorylation was normal.

Study of the Lys460Glu and Ser462Asn mutant receptors has previously shown that some $\alpha$ subunit mutations result in impaired cooperativity in insulin binding, or in altered $\mathrm{pH}$-dependence of insulin dissociation $[8,9]$. In the case of the Ile119Met mutant, insulin dissociation was slightly slower at baseline than that from wild-type receptor; however both positive and negative cooperativity were preserved. The impaired dissociation rate was accentuated, however, under acidic conditions. This would be predicted to favour degradation of insulin-receptor complexes in acidified endosomes after internalisation in vivo, and reduce the amount of receptor recycling to the cell surface, which requires insulin dissociation. Substitution of

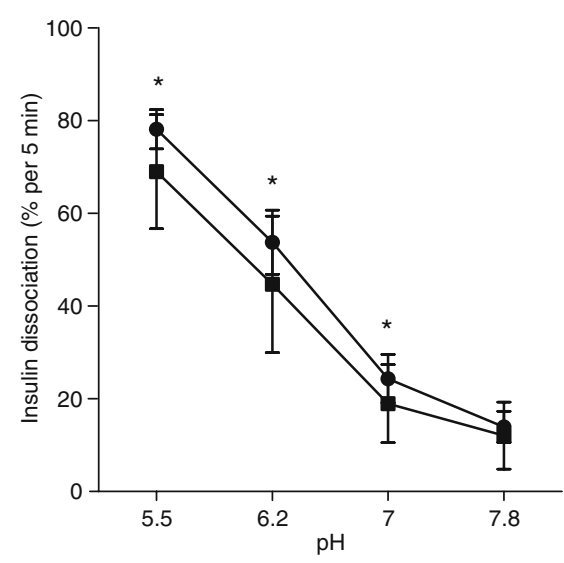

Fig. 5 Effect of $\mathrm{pH}$ on dissociation of ${ }^{125}$ I-insulin from the Ile119Met and wild-type insulin receptors. $\mathrm{pH}$ dependency of insulin dissociation is shown for wild-type and mutant insulin receptors overexpressed in CHO cells $(* p<0.05$. Ile119Met, circles; wild-type, squares)
0.05 error bars shown in grey; Ile119Met: downward black triangle, no insulin; white triangle $0.1 \mu \mathrm{mol} / 1$ insulin; upward black triangle, $10 \mu \mathrm{mol} / \mathrm{l}$ insulin. Wild-type: black square, no insulin; white square, $0.1 \mu \mathrm{mol} / 1$ insulin; black diamond, $10 \mu \mathrm{mol} / 1$ insulin)

Ile119 by methionine is predicted to alter the packing within the barrel of the L1 domain only modestly, potentially leading to compensation in the sheet structure itself. However Ile119 is neighboured by $\operatorname{Arg} 118$ and Glu120, both of which have recently been shown to play a key role in creating so-called site 1 for insulin binding to the receptor through formation of a charge compensating cluster with residues Glu698 and Arg702from the C terminal alpha helix of the alpha subunit [25]. In this key structural context it is plausible that substitution of Ile119 for methionine may perturb some aspect of the dynamic interaction of the alpha subunit with insulin. Nevertheless, our functional studies are not comprehensive, and it remains possible that a further, unstudied aspect of insulin receptor function is selectively affected by the Ile119Met mutation, or that this mutation may have a greater deleterious effect in the context of the longer ' $\mathrm{B}$ ' isoform of the insulin receptor that includes the small exon 11. In particular, it would be of interest to study surface distribution of the insulin receptor and insulin-dependent receptor internalisation, processes that have been shown to be impaired by another alpha subunit mutation, albeit one affecting the cysteine-rich domain rather than the L1 domain [11].

The current wealth of genome-wide association studies revealing statistical associations between disease traits and common genetic variants has led to keen interest in trying to assign specific functional consequences to each such variant. In this context it is sobering to reflect that, despite the compelling case for defective insulin receptor function in the patients studied, and the wealth of understanding of insulin receptor function, it has proved extremely difficult to demonstrate a defect in insulin signalling in vitro commensurate with the clinical severity of the phenotype. This emphasizes the challenges that lie ahead in translating pure genetic associations into cellular disease mechanism. 
In summary, we provide evidence that the Ile119Met INSR mutation is a loss-of-function mutation that causes autosomal recessive extreme insulin resistance, with a strong founder effect in the region of the Horn of Africa. We thus suggest that any patient of Yemeni or Somali origin who presents with extreme insulin resistance should be screened first for this allele. The Ile119Met insulin receptor shows normal steady state insulin binding and autophosphorylation in response to insulin, but mildly perturbed proreceptor processing and insulin dissociation, particularly in acidic conditions.

Acknowledgements This work was funded by the Wellcome Trust (E. Raffan, Clinical Research Training Fellowship 087678/Z/08/Z; I. Barroso, 077016/Z/05/Z; R.K. Semple, Intermediate Clinical Fellowship 080952/Z/06/Z; S. O‘Rahilly, Programme Grant 078986/Z/06/Z), the UK NIHR Cambridge Biomedical Research Centre, and the UK Medical Research Council Centre for Obesity and Related Metabolic Diseases.

Duality of interest statement I. Barroso and her spouse own stock in the companies GlaxoSmithKline (GSK) and Incyte (INCY). The remaining authors declare that there is no duality of interest associated with this manuscript.

Open Access This article is distributed under the terms of the Creative Commons Attribution Noncommercial License which permits any noncommercial use, distribution, and reproduction in any medium, provided the original author(s) and source are credited.

\section{References}

1. Doria A, Patti ME, Kahn CR (2008) The emerging genetic architecture of type 2 diabetes. Cell Metab 8:186-200

2. Garg A, Wilson R, Barnes R et al (1999) A gene for congenital generalized lipodystrophy maps to human chromosome 9q34. J Clin Endocrinol Metab 84:3390-3394

3. Musso C, Cochran E, Moran SA et al (2004) Clinical course of genetic diseases of the insulin receptor (type A and Rabson-Mendenhall syndromes): a 30-year prospective. Medicine (Baltimore) 83:209-222

4. Semple RK, Savage DB, O'Rahilly S (2010) Syndromes of severe insulin resistance and/or lipodystrophy. In: Weiss RE, Refetoff E (eds) Genetic diagnosis of endocrine disorders. Elsevier, London, pp 39-52

5. Kadowaki T, Bevins CL, Cama A et al (1988) Two mutant alleles of the insulin receptor gene in a patient with extreme insulin resistance. Science 240:787-790

6. Yoshimasa Y, Seino S, Whittaker J et al (1988) Insulin-resistant diabetes due to a point mutation that prevents insulin proreceptor processing. Science 240:784-787

7. Taylor SI, Cama A, Accili D et al (1992) Mutations in the insulin receptor gene. Endocr Rev 13:566-595
8. Kadowaki H, Kadowaki T, Cama A et al (1990) Mutagenesis of lysine 460 in the human insulin receptor. Effects upon receptor recycling and cooperative interactions among binding sites. J Biol Chem 265:21285-21296

9. Cama A, Sierra ML, Kadowaki T et al (1995) Two mutant alleles of the insulin receptor gene in a family with a genetic form of insulin resistance: a 10 base pair deletion in exon 1 and a mutation substituting serine for asparagine-462. Hum Genet 95:174-182

10. McKern NM, Lawrence MC, Streltsov VA et al (2006) Structure of the insulin receptor ectodomain reveals a folded-over conformation. Nature 443:218-221

11. Hamer I, Foti M, Emkey R et al (2002) An arginine to cysteine (252) mutation in insulin receptors from a patient with severe insulin resistance inhibits receptor internalisation but preserves signalling events. Diabetologia 45:657-667

12. Hone J, Accili D, al-Gazali LI, Lestringant G, Orban T, Taylor SI (1994) Homozygosity for a new mutation (Ile119 $\rightarrow$ Met) in the insulin receptor gene in five sibs with familial insulin resistance. $\mathrm{J}$ Med Genet 31:715-716

13. al-Gazali LI, Khalil M, Devadas K (1993) A syndrome of insulin resistance resembling leprechaunism in five sibs of consanguineous parents. J Med Genet 30:470-475

14. Agostini M, Schoenmakers E, Mitchell C et al (2006) Non-DNA binding, dominant-negative, human PPARgamma mutations cause lipodystrophic insulin resistance. Cell Metab 4:303-311

15. Sanchez JJ, Phillips C, Borsting C et al (2006) A multiplex assay with 52 single nucleotide polymorphisms for human identification. Electrophoresis 27:1713-1724

16. The International HapMap Consortium (2003) The International HapMap Project. Nature 426:789-796

17. Guex N, Peitsch MC (1997) SWISS-MODEL and the SwissPdbViewer: an environment for comparative protein modeling. Electrophoresis 18:2714-2723

18. Lou M, Garrett TP, McKern NM et al (2006) The first three domains of the insulin receptor differ structurally from the insulin-like growth factor 1 receptor in the regions governing ligand specificity. Proc Natl Acad Sci USA 103:12429-12434

19. Semple RK, Sleigh A, Murgatroyd PR et al (2009) Postreceptor insulin resistance contributes to human dyslipidemia and hepatic steatosis. J Clin Invest 119:315-322

20. Semple RK, Cochran EK, Soos MA et al (2008) Plasma adiponectin as a marker of insulin receptor dysfunction: clinical utility in severe insulin resistance. Diabetes Care 31:977-979

21. Gregorius HR (1980) The probability of losing an allele when diploid genotypes are sampled. Biometrics 36:643-652

22. De Meyts P (1976) Cooperative properties of hormone receptors in cell membranes. J Supramol Struct 4:241-258

23. Taylor SI, Leventhal S (1983) Defect in cooperativity in insulin receptors from a patient with a congenital form of extreme insulin resistance. J Clin Investig 71:1676-1685

24. Wang CC, Goldfine ID, Fujita-Yamaguchi Y, Gattner HG, Brandenburg D, De Meyts P (1988) Negative and positive sitesite interactions, and their modulation by $\mathrm{pH}$, insulin analogs, and monoclonal antibodies, are preserved in the purified insulin receptor. Proc Natl Acad Sci USA 85:8400-8404

25. Smith BJ, Huang K, Kong G et al (2010) Structural resolution of a tandem hormone-binding element in the insulin receptor and its implications for design of peptide agonists. Proc Natl Acad Sci USA 107:6771-6776 